\author{
Marian GIŻEJOWSKI ${ }^{1}$ \\ Radosław SZCZERBA ${ }^{2}$ \\ Marcin GAJEWSKI ${ }^{3}$
}

\title{
NUMERYCZNA OCENA NOŚNOŚCI BELEK STALOWYCH ZGINANYCH DWUKIERUNKOWO
}

\begin{abstract}
W pracy przedstawiono metody symulacji MES przy szacowaniu nośności stalowych belek dwuteowych poddanych dwukierunkowemu zginaniu ze zwichrzeniem. Analizie nośności granicznej poddano belki z imperfekcjami geometrycznymi. Wykorzystano geometrycznie i materiałowo nieliniowe sformułowanie (GMNIA), w którym wykorzystane są wyniki analiz liniowych (LBA) w celu określania imperfekcji. Ścieżki równowagi statycznej w fazie przed- i pogranicznej wyznaczano przy użyciu algorytmów przyrostowo-iteracyjnych o sterowaniu parametrem obciążenia lub przemieszczenia, wykorzystując metody NewtonaRaphsona oraz Riksa. Obliczenia numeryczne wykonano z zastosowaniem programu komputerowego ABAQUS/Standard. Omówiono sposób modelowania warunków brzegowych oraz wpływ realizacji obciążenia na uzyskiwane wyniki.
\end{abstract}

Słowa kluczowe: dwuteownik stalowy, zwichrzenie, ścieżka równowagi statycznej, punkt graniczny, MES, GMNIA

\section{Wprowadzenie}

Zagadnienie nośności realnych belek (z imperfekcjami) dwukierunkowo zginanych, wrażliwych na zwichrzenie jest w ogólności złożone i ocena ich wytężenia wymaga uwzględnienia następujących czynników:

- wpływu oddziaływań, które mogą pochodzić od kombinacji obciążeń ze zmieniającymi się niezależnie składnikami,

- zależności wytrzymałości od poziomu wytężenia belki pod wpływem zginania względem obu osi bezwładności przekroju.

\footnotetext{
${ }^{1}$ Autor do korespondencji/corresponding author: Marian Giżejowski, Politechnika Warszawska, al. Armii Ludowej 16, 00-637 Warszawa, tel.: +48 22234 6554, m.gizejowski@il.pw.edu.pl

${ }^{2}$ Radosław Szczerba, Politechnika Warszawska, al. Armii Ludowej 16, 00-637 Warszawa, tel.: +48 22234 6261, r.szczerba@il.pw.edu.pl

${ }^{3}$ Marcin Gajewski, Politechnika Warszawska, al. Armii Ludowej 16, 00-637 Warszawa, tel.: +48 22234 5164, m.gajewski@il.pw.edu.pl
} 
Oba ww. czynniki prowadzą do silnie nieliniowych zależności interakcyjnych $m_{b y}=M_{y, E d, \text { max }} / M_{b y, R k}$ i $m_{c z}=M_{z, E d \text {, max }} / M_{c z, R k}$. Symulacje numeryczne MES pozwalające na wyznaczenie tych zależności mogą być przeprowadzone z uwzględnieniem różnych metod i algorytmów numerycznych zaimplementowanych w komercyjnych programach obliczeniowych. W niniejszej pracy zastosowano wybrane metody i przedstawiono ocenę wiarygodności wyników symulacji, a także rekomendacje odnoszące się do praktycznych aspektów numerycznego modelowania statecznościowego zachowania się elementów realnych konstrukcji stalowych.

\section{Metody symulacji MES w zagadnieniach stateczności}

Układ równań nieliniowych powstałych w wyniku dyskretyzacji MES rozwiązuje się efektywnie różnymi metodami przyrostowo-iteracyjnymi w przestrzeni obciążeniowej, przemieszczeniowej lub obciążeniowoprzemieszczeniowej, które pozwalają na wyznaczenie pełnej ścieżki równowagi, przed- i pogranicznej wraz z identyfikacją punktów bifurkacji i punktów granicznych, lokalnych i globalnych [2]. W programie ABAQUS [3] możliwe jest wyznaczenie:

a) wartości i wektorów własnych (tzw. liniowa stateczność ustrojów perfekcyjnych - LBA),

b) nośności ustrojów bez imperfekcji z uwzględnieniem dużych deformacji, modelując materiał jako sprężysty (GNA) lub niesprężysty (GMNA),

c) nośności ustrojów z imperfekcjami z uwzględnieniem dużych deformacji, modelując materiał jako sprężysty (GNIA) lub niesprężysty (GMNIA).

$\mathrm{W}$ przypadkach a) oraz b) stosuje się algorytmy przyrostowo-iteracyjne Newtona i Newtona-Raphsona o sterowaniu parametrem w przestrzeni obciążeń lub przemieszczeń oraz Riksa o przyrostowym sterowaniu parametrem obciążenia lub przemieszczenia wraz $\mathrm{z}$ iteracją $\mathrm{W}$ przestrzeni obciążeniowoprzemieszczeniowej.

W algorytmach typu Newtona ze sterowaniem przyrostami obciążenia istnieje możliwość analizowania stanów równowagi jedynie do chwili osiągnięcia na globalnej ścieżce równowagi punktu granicznego. Algorytmy te, w wypadku sterownia przyrostem przemieszczenia, mogą być efektywnie wykorzystywane do wyznaczenia pełnej ścieżki równowagi konstrukcji jako zależności funkcyjnej między reakcją więzi odpowiadającej zadawanemu przyrostowi przemieszczenia oraz wartością całkowitego przemieszczenia w stanie równowagi na danym kroku. Jeżeli oddziaływania są zależne, sterowanie większą liczbą składników pola przemieszczenia wymaga ustalenia relacji między tymi składnikami, która pozostaje niezmienna $\mathrm{w}$ procesie przyrostowego śledzenia ścieżki równowagi konstrukcji. Sterowanie analizą odbywa się poprzez przyrost parametru przemieszczenia, wspólnego dla wszystkich wymuszeń kinematycznych. Sytuacja ta powoduje, że reakcje więzów uzyskane w wyniku przeprowadzonej symulacji spręży- 
sto-plastycznej odpowiedzi konstrukcji nie pozostają w tej samej relacji jaka została założona do ustalenia relacji między wymuszeniami kinematycznymi.

Jeżeli wymuszenia kinematyczne są niezależne, analizę przeprowadzić można sekwencyjnie, przyjmując sekwencję wymuszeń kinematycznych najbardziej niekorzystną z punktu widzenia nośności konstrukcji. W wypadku elementu swobodnie podpartego, ściskanego i zginanego dwukierunkowo, możliwe są trzy wymuszenia kinematyczne: skrócenie oraz dwa obroty podpór względem przekrojowych osi głównych. Możliwe jest 6 kombinacji sekwencyjnej realizacji procesu przyrostowego, związanych w każdej kombinacji z innym porządkiem kolejno realizowanych przyrostów składnika pola niezależnych wymuszeń kinematycznych. W każdej kombinacji zadajemy wartości reakcji więzów w dwóch pierwszych sekwencjach realizacji przyrostów odpowiadających im wymuszeń kinematycznych, w trzeciej zaś przyrosty realizowane są do chwili osiągnięcia punktu granicznego na ścieżce równowagi (reakcja więzi wyznaczona w ostatnim etapie sekwencji jest trzecią współrzędną punktu na powierzchni granicznej). Powtarzając symulacje dla różnych wartości reakcji więzów w dwóch pierwszych sekwencjach realizacji przyrostów wymuszeń kinematycznych otrzymujemy powierzchnię graniczną nośności z uwzględnieniem wyboczenia i zwichrzenia elementu. Zadanie można też zrealizować stosując algorytm Riksa i zadając jednocześnie 3 wymuszenia kinematyczne, ale przy ustaleniu relacji między nimi, która pozostaje niezmienna w procesie przyrostowego śledzenia ścieżki równowagi konstrukcji. Powierzchnia graniczna jest miejscem geometrycznym punktów o współrzędnych odpowiadających reakcjom więzów, związanym z graniczną wartością parametru sterowania wymuszeniami kinematycznymi.

Dogodnym sposobem symulacji jest ustalenie wartości pewnych składników oddziaływań a priori i prowadzenie symulacji przy jednym wymuszeniu kinematycznym lub przy dwóch sprzężonych wymuszeniach kinematycznych, odpowiadających schematowi symetrycznemu lub antysymetrycznemu przebiegu efektu oddziaływania na długości elementu. Załóżmy, że mamy do czynienia z obciążeniem belki dwoma składnikami, z których jeden daje niesymetryczny przebieg efektu oddziaływania, np. obciążenie momentem skupionym $F_{x z, d}$ na jednym końcu, dające trójkątny wykres momentowego efektu $M_{z, E d}$. Przyjmijmy, że składnik obciążenia $F_{x z, d}$ ma ustaloną wartość, a sterowanie parametrem przemieszczenia odpowiada dwóm wymuszeniom kinematycznym przykładanym jednocześnie, z założenia dającym symetryczny lub antysymetryczny przebieg reakcji więzów $R_{x y, d}$ (efektu oddziaływania $M_{y, E d}$ ), np. obroty $\theta_{y, d}$ odpowiadające obciążeniu dwoma momentami skupionymi $F_{x y, d}$. Osiągnięcie punktu granicznego nie będzie w tym wypadku odpowiadało dwóm reakcjom więzów o tej samej wartości bezwzględnej, dającym założony przebieg efektu oddziaływań $M_{y, E d}$ jako symetryczny lub antysymetryczny. Należy więc pamiętać o ograniczeniach stosowanego modelowania zachowania się konstrukcji w przypadku oddziaływań wieloparametrowych $\mathrm{z}$ zastosowaniem algorytmów sterowania przemieszczeniowego. 


\section{O interpretacji wyników powłokowego modelowania elemen- tów belkowych przez siły uogólnione - realizacja warunków brzegowych}

Porównując rozwiązania numeryczne MES uzyskane $\mathrm{z}$ wykorzystaniem modeli prętowych i modeli powłokowych należy zadbać o to, aby warunki realizacji warunków brzegowych i obciążenia były identyczne w obu sposobach modelowania. W modelu powłokowym należy wówczas spełnić założenie sztywnego konturu przyjmowane w teorii pręta cienkościennego Własowa, które wymaga, aby deplanacja była liniowo-zmienna na długości ścianek przekroju i stała na ich grubości. Można to osiągnąć przez wyodrębnienie trzech subkonturów jak zaproponowano w [4]. Należy zauważyć, że w tego typu modelowaniu efekty naprężeń normalnych od zginania i skręcania skrępowanego generowane są jedynie w pasach przekroju dwuteowego. Obciążenie skupione momentem $F_{x z, d}$ na końcu pręta, w środku ciężkości przekroju, należy wówczas zastąpić dwoma równoważnymi momentami w pasach $F_{x z, f d}$, których wartość wynosi $F_{x z, d} / 2$. $\mathrm{W}$ algorytmach sterowania wymuszeniem kinematycznym należy mieć na uwadze, że pasy belki dwuteowej przenoszą uogólnione siły przekrojowe $S_{z, R d}$, które są wypadkową stanu wywołanego zginaniem i skręcaniem skrępowanym. Przy sterowaniu obrotami $\theta_{z, f d}$ pasów bisymetrycznego przekroju dwuteowego, reakcje w więzach pasa górnego i dolnego odpowiadają złożonemu stanowi, a więc siłom przekrojowym od zginania i skręcania skrępowanego względem osi głównej $z$ przekroju:

$$
S_{z, R d}^{t}=\int_{A_{f}}\left(\sigma_{x, f t} y\right) d y d z, S_{z, R d}^{b}=\int_{A_{f}}\left(\sigma_{x, f b} y\right) d y d z
$$

gdzie: $S_{z, R d}^{t}$ oraz $S_{z, R d}^{b}$ odpowiadają naprężeniom normalnym $\sigma_{x}(z)$, odpowiednio $\sigma_{x, f t}(y)$ w pasie górnym i $\sigma_{x, f b}(y)$ w pasie dolnym, scałkowanym na szerokości pasów, $A_{f}$ - pole przekroju pasa.

Rozseparowanie stanów giętych w pasach górnym , ff " i dolnym , ff $b$ " od zginania momentem $M_{z, R d}$ oraz skręcania skrępowanego bimomentem $B_{R d}$ można w prosty sposób dokonać w wypadku, gdy najwcześniej osiągany punkt graniczny ścieżek równowagi sił przekrojowych w pasach górnym $S_{z, R d}^{t}$ oraz dolnym $S_{z, R d}^{b}$ jest stowarzyszony ze stanem sprężystym belki. Zachodzą wówczas zależności:

$$
M_{z, R d}=2 M_{z f, R d}, B_{R d}=M_{z f, R d}^{B} h_{f},
$$

oraz

$$
M_{z f, R d}=0,5\left(S_{z, R d}^{t}+S_{z, R d}^{b}\right), M_{z f, R d}^{B}=0,5\left(S_{z, R d}^{t}-S_{z, R d}^{b}\right),
$$

gdzie: $h_{f}$ jest wysokością przekroju dwuteowego w osiach pasów. 
Sposób rozseparowania efektów oddziaływań zastosowano w rozdziale 4 , dotyczącym oceny nośności belki dwukierunkowo zginanej, p. 4.2 przypadek a).

\section{Przykłady powłokowego modelowania elementów belkowych zginanych dwukierunkowego}

Przyjęto następujące założenia do prowadzonych analiz:

a) rozpatrzono element o smukłości $\overline{\lambda_{z}}=1,0$ i przekroju HEB 300 ,

b) przyjęto stały rozkład momentu zginającego względem rozpatrywanych osi głównych, oznaczony UMI, I = Y, Z,

c) rozpatrzono belkę o geometrii imperfekcyjnej i kształcie imperfekcji odpowiadającym pierwszej formie utraty stateczności z warunku zwichrzenia pod wpływem momentu $M_{y, E d}$, przy czym amplituda imperfekcji jest zgodna z zaleceniami PN-EN 1993-1-1 [1],

d) gatunek stali S235, co daje: $M_{p l, y, R k}=420,8 \mathrm{kNm}, M_{p l, z, R k}=202,8 \mathrm{kNm}$,

e) symulacje MES prowadzone są z wykorzystaniem programu ABAQUS [3], po przyjęciu prostokątnych elementów powłokowych S4R oraz warunków brzegowych odtwarzających założenia przyjmowane w teorii pręta cienkościennego Własowa,

f) założono $m_{c z}=M_{z, E d} d M_{z, p l, R k}=0,200$ i symulowano stan technicznej utraty stateczności (zwichrzenia) z wykorzystaniem algorytmów numerycznych Newtona-Raphsona oraz Riksa w celu wyznaczenia $m_{b y}=\max \left(M_{y, E d} l M_{y, p l, R k}\right)$,

g) przyjęto trzy sekwencje realizacji obciążeń:

- sekwencja A (ustalona wartość momentów w pasach $F_{x z, f d}=F_{x z, d} d 2$, przyrosty $F_{x y, d}$ realizowane przez sterowanie obrotem przekroju $\left.\theta_{y, d}\right)$.

- sekwencja B (ustalona wartość $F_{x y, d}$, przyrosty $F_{x z, d}$ realizowane przez sterowanie obrotami pasów $\left.\theta_{z, f d}\right)$,

- sekwencja $\mathbf{C}$ (przyrosty $F_{x y, d}$ i $F_{x z, d}$, realizowane przez sterowanie parametrem obciążenia zgodnie $\mathrm{z}$ kierunkiem linii nachylenia ścieżki o stosunku $\left.m_{c z /} m_{b y}=0,200 / 0,721\right)$.

\subsection{Wyniki dotyczące sekwencji A}

W kroku pierwszym w przekrojach końcowych zadano po dwa momenty skupione o wartościach $F_{x z, d} / 2 \mathrm{w}$ środkach ciężkości pasów, dające stały moment $M_{z, E d}=40,557 \mathrm{kNm}$, który opowiada wartości bezwymiarowej $m_{c z}=0,200$.

W kroku drugim zastosowano:

a) sterowanie obrotem przekrojów końcowych $\mathrm{z}$ wykorzystaniem algorytmu Newtona-Raphsona (obrót $\theta_{y}$ przyłożony w środku ciężkości przekroju). Na podstawie ścieżki równowagi statycznej wyznaczono: $M_{y, E d, \max }=\mathrm{RMY}_{\max }=$ $303,490 \mathrm{kNm}$, co daje $m_{c y}=0,721$ (rys. 1a),

b) sterowanie obciążeniowe z wykorzystaniem algorytmu Riksa (moment skupiony $F_{x y, d}$ przyłożony w środku ciężkości przekroju). Uzyskano $M_{y, E d, \max }=$ $\mathrm{CMY}_{\max }=303,479 \mathrm{kNm}$, co daje $m_{c y}=0,721$ (rys. $1 \mathrm{~b}$ ). 

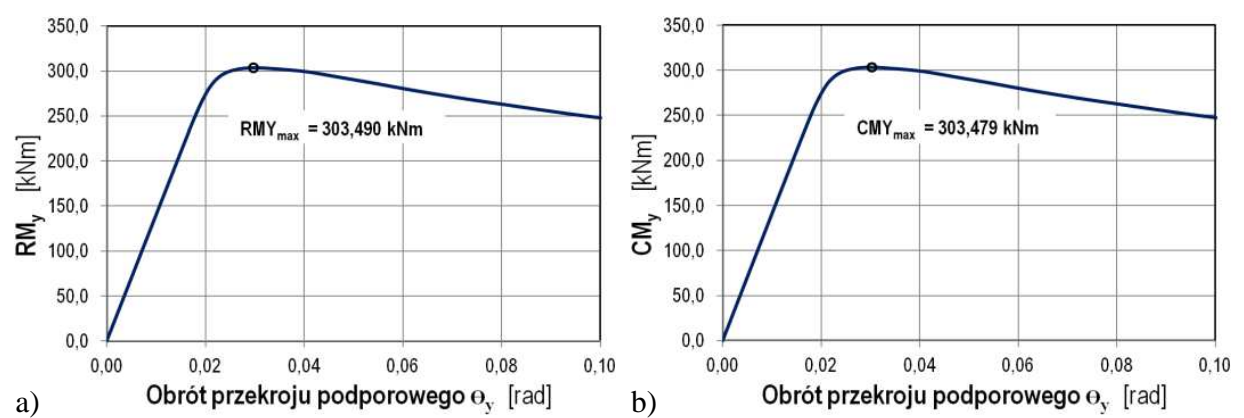

Rys. 1. Wyniki dotyczące sekwencji A; a) sterowanie obrotem przekrojów podporowych (algorytm Newtona-Raphsona); b) sterowanie obciążeniem (algorytm Riksa)

Fig. 1. Results concerning sequence A; a) controlling of end cross-sections rotation (NewtonRaphson algorithm); b) controlling of load parameter (Riks algorithm)

\subsection{Wyniki dotyczące sekwencji B}

W kroku pierwszym w przekrojach końcowych zadano momenty skupione o wartości $F_{x y, d}$ w środkach ciężkości przekrojów końcowych, dające stały moment $M_{y, E d}=303,490 \mathrm{kNm}$, który odpowiada wartości bezwymiarowej $\mathrm{m}_{\mathrm{cy}}=0,721$. W drugim kroku zastosowano:

a) sterowanie obrotem pasów (obroty $\theta_{z}$ przyłożono w środkach ciężkości pasów) przekrojów końcowych $\mathrm{z}$ wykorzystaniem algorytmu NewtonaRaphsona. Przyrosty wymuszenia dla pasa górnego i dolnego są takie same. Uzyskano dwie różne ścieżki równowagi reakcji odpowiadających wymuszeniom obrotowym $\theta_{z}$ pasów górnego i dolnego (rys. 2a). W przypadku pasa górnego, maksimum reakcji wynosi $\mathrm{RMZ}-\mathrm{ft}_{\max }=10,009 \mathrm{kNm}$, zaś odpowiadająca mu wartość reakcji pasa dolnego wynosi RMZ-fb $\mathrm{for}_{\text {cor }}=30,432 \mathrm{kNm}$. Otrzymuje się: $M_{z, E d, \max }=10,009+30,432=40,441 \mathrm{kNm}$, co daje $m_{c z}=0,199$,
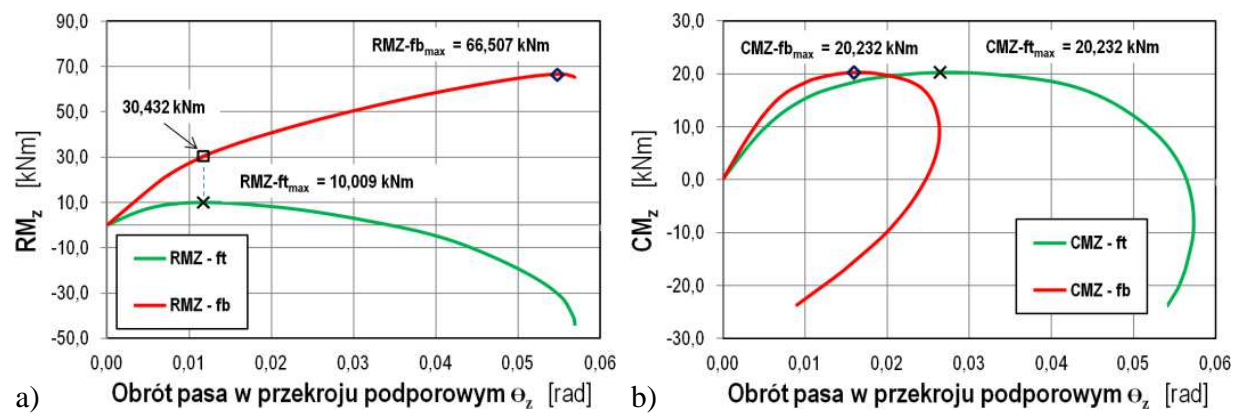

Rys. 2. Wyniki dotyczące sekwencji B; a) sterowanie obrotem pasów w przekrojach podporowych (algorytm Newtona-Raphsona); b) sterowanie obciążeniem (algorytm Riksa)

Fig. 2. Results concerning sequence B; a) controlling of flanges rotation in end cross-sections (Newton-Raphson algorithm); b) controlling of load parameter (Riks algorithm) 
b) sterowanie obciążeniowe z wykorzystaniem algorytmu Riksa (momenty skupione $F_{x z, d} / 2 \mathrm{w}$ środkach ciężkości pasów). Uzyskano $M_{z, E d, \max }=\mathrm{CMZ}-\mathrm{ft}_{\max }$ $+\mathrm{CMZ}-\mathrm{fb}_{\max }=20,232+20,232=40,464 \mathrm{kNm}$, co daje $m_{c z}=0,200$ (rys. 2 b).

\subsection{Wyniki dotyczące sekwencji C}

W jednym kroku zadawano składniki niestatecznościowy $F_{x z, d}$ (momenty skupione $F_{x z, d} / 2 \mathrm{w}$ środkach ciężkości pasów) i statecznościowy $F_{x y, d}$ (moment skupiony $F_{x y, d}$ W środku ciężkości przekroju). W punkcie granicznym uzyskano $M_{y, E d, \max }=\mathrm{CMY}_{\max }=303,345 \mathrm{kNm}$, co daje $m_{c y}=0,721, M_{z, E d, \max }=\mathrm{CMZ}-\mathrm{ft}_{\max }$ + CMZ-fb $b_{\max }=20,269+20,269=40,538 \mathrm{kNm}$, więc $m_{c z}=0,200$ (rys. 3).

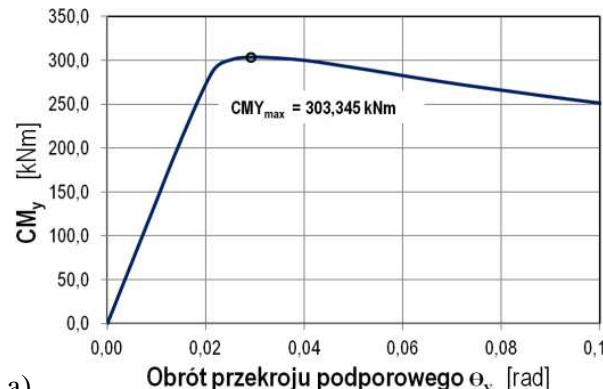

a)

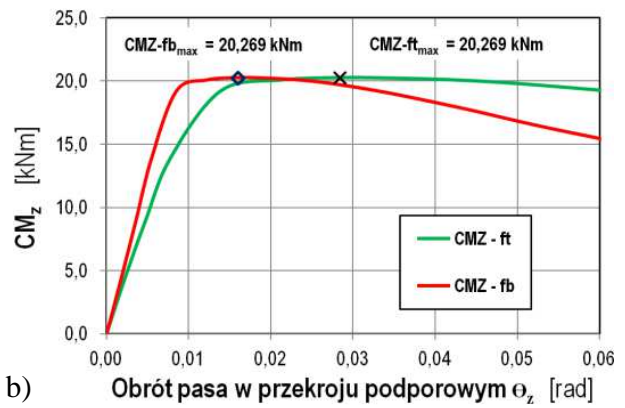

Rys. 3. Wyniki dotyczące sekwencji C (sterowanie parametrem obciążenia wg algorytmu Riksa); a) moment zginający względem osi $y$; b) moment zginający względem osi $z$

Fig. 3. Results concerning sequence $\mathrm{C}$ (controlling of load parameter according to Riks algorithm); a) bending moment about axis $y-y$; b) bending moment about axis $z-z$

\section{Podsumowanie}

W pracy przedstawiono metody symulacji MES przy szacowaniu nośności elementów dwukierunkowo zginanych ze zwichrzeniem. Omówiono sposób modelowania warunków brzegowych oraz wpływ zastosowania różnych sekwencji obciążeń na wyniki symulacji. Ścieżki równowagi statycznej wyznaczano przy użyciu algorytmów przyrostowo-iteracyjnych o sterowaniu parametrem obciążenia lub przemieszczenia, wykorzystując metody Newtona-Raphsona oraz Riksa. Ze względu na wskazane w pracy ograniczenia modelowania statecznościowego zachowania się elementu na podstawie sterowania parametrem przemieszczeniowym, jego poprawność należy weryfikować przez porównanie z wynikami analizy, w której sterowanie parametrem obciążenia realizowane jest przyrostowo zgodnie z algorytmem Riksa.

Rezultaty przeprowadzonych analiz stanowią punkt wyjścia do bardziej zaawansowanych rozważań, dotyczących obliczania realnych ustrojów konstrukcyjnych. 


\section{Literatura}

[1] PN-EN 1993-1-1: Eurokod 3 - Projektowanie konstrukcji stalowych. Część 1-1: Reguły ogólne i reguły dla budynków.

[2] Waszczyszyn Z., Cichoń Cz., Radwańska M.: Metoda elementów skończonych w stateczności konstrukcji, Arkady, Warszawa 1990.

[3] ABAQUS Theory Manual, Version 6.11, Dassault Systèmes, 2011.

[4] Giżejowski, M., Szczerba, R., Gajewski, M.: Modele MES i metody symulacji w analizie zwichrzenia zginanych elementów konstrukcji stalowych, 62. Konferencja Naukowa KILiW PAN i KN PZITB, Krynica-Zdrój, 11-16 września 2016.

\section{NUMERICAL ASSESSMENT OF STEEL I-SECTION BEAMS RESISTANCE IN RELATION TO TWO DIRECTIONAL BENDING}

\section{S u m m a r y}

FEM simulation methods used for assessment of steel I-section beams resistance in relation to two directional bending and LT-buckling are presented in the paper. Stability analyses are concerned with beams of imperfect geometry. Geometrically and materially nonlinear analyses GMNIA preceded by analyses LBA were carried out. Static equilibrium paths accounting for preand postlimit behaviour were determined with use of incremental-iterative algorithms taking into consideration both the load and displacement control parameters. Newton-Raphson and Riks methods were used for this purpose. Numerical simulations were conducted with use of ABAQUS/ Standard program. Modelling techniques of boundary conditions and load application sequence were presented.

Keywords: steel I-section beam, LT buckling, static equilibrium path, limit point, FEM, GMNIA

Przestano do redakcji: 07.06.2016 $r$.

Przyjęto do druku: 30.06.2016 r.

DOI: $10.7862 / \mathrm{rb} .2016 .41$ 